\title{
O “TOURBILLON” SOCIAL: A REPRESENTAÇÃO DA CIDADE MODERNA NA POESIA DE ALLEN GINSBERG E ROBERTO PIVA ${ }^{1}$
}

\author{
THE SOCIAL “TOURBILLON”: THE REPRESENTATION OF THE \\ MODERN CITY IN ALLEN GINSBERG'S AND ROBERTO PIVA'S \\ POETRY
}

\author{
Patrícia Lochini ${ }^{2}$ \\ Paulo Andrade ${ }^{3}$
}

\begin{abstract}
Resumo: A desordem quantitativa que caracteriza a modernidade, personificada pelo ambiente urbano, afeta a subjetividade dos indivíduos que nela estão inseridos, e, consequentemente, as suas relações, que sofrem com a alienação dos sentimentos. O pensamento romântico do século XIX, como crítica à realidade burguesa, expõe o vazio existencial do sujeito que se sente desajustado à vida moderna. E no século $\mathrm{XX}$ esse espírito ainda ilumina a mente dos poetas, que continuam na busca por formas de se colocar em oposição à desumanização do homem. Desta forma, este artigo tem como objetivo refletir, por meio da análise comparativa, como a poesia da segunda metade do século XX encena o sentimento de revolta, romântico por excelência, à cidade como ambiente de alienação, partindo dos modernistas da década de 50, representados pelo poeta beatnik norte-americano Allen Ginsberg, para compreender os modernistas da década de 60, representados pelo poeta brasileiro Roberto Piva.
\end{abstract}

Palavras-chave: modernidade, cidade, romantismo, resistência, poesia moderna, geração beat

Abstract:The quantitative disorder which characterizes the modernity, personified by the urban environment, touch the subjectivity of man who are inserted in it, and, consequently, their relationships, which suffer with the alienation of sentiments. The romantic thought of the XIX century, as a criticism to bourgeois reality, expose the empty existential of the subject that feels misfit to modern life. And, in the XX century, that spirit still illuminate the mind of the poets which keep in the search for ways to put on opposition to dehumanization of man. This way, this article have as objective reflect, by comparative analysis, how the poetry of the second half of XX century stages the sentiment of revolt, romantic par excellence, against the city as an environment of alienation, from the modernists of 50's, represented

1 O presente trabalho foi realizado com apoio da Coordenação de Aperfeiçoamento de Pessoal de Nível Superior - Brasil (CAPES) - Código de Financiamento 001

Trabalho apresentado no VII Encontro Nacional de Estudos da Imagem e IV Encontro Internacional de Estudos da Imagem - UEL - Londrina/PR

2 Mestranda no Programa de Pós-Graduação em Estudos Literários da UNESP/Araraquara, na área de Teoria e Crítica da Poesia. Possui graduação em Letras pela UNESP/Assis. E-mail: pvlochini@gmail.com

3 Professor do Departamento de Literatura da UNESP/Araraquara, na área de Teoria da Literatura e no Programa de Pós-Graduação em Estudos Literários. E-mail: paulo.andrade@unesp.br 
by the American beatnik poet Allen Ginsberg, to understand the modernists of 60 's, represented by the Brazilian poet Roberto Piva.

Keywords: modernity, city, romanticism, resistance, modern poetry, beat generation.

A partir da Revolução Industrial, com o desenvolvimento e expansão da lógica moderno-capitalista, as rápidas e intensas mudanças na estrutura espacial e temporal da sociedade, resultante do crescimento das cidades e do estabelecimento de novas formas de organização e interação social, provocaram mudanças também na estrutura subjetiva do indivíduo. O declínio dos valores qualitativos em prol dos valores quantitativos, o éthos do capitalismo industrial moderno, desperta no sujeito o sentimento de perda desses valores humanos, que foram alienados. O indivíduo, carente da sua união primordial com a natureza e com o outro, constata que algo foi perdido, em nível individual e coletivo.

Sob as ruínas dos vínculos sociais, crescem incessantemente paredes de concreto em

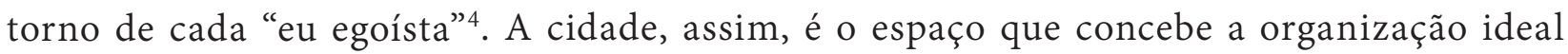
para a nova ordem social, de forma a isolar os sujeitos dentro de suas determinadas funções sociais.

A ideia de comunidade, de um coletivo que compõe um organismo vivo, perde-se com o desenvolvimento de um conjunto artificial denominado sociedade. A artificialidade da sociedade deriva do fato de que ela é constituída de forma a colaborar ao funcionamento da maquinaria capitalista. Assim, o indivíduo se sente exilado de seu ambiente natural, inserido em um ambiente sintético, do qual ele não se sente parte.

O pensamento romântico, como crítica à realidade burguesa, expõe o vazio existencial do sujeito que se sente desajustado à vida moderna. De acordo com Arnold Hauser, "o sentimento de privação do lar (Heimatslosigkeit) e isolamento tornou-se a experiência fundamental" dos românticos do início do século XIX" esse sentimento de exílio. Em “O Princípio Esperança” (1954), ao criticar voraz lógica do lucro que permeia todas as relações modernas, Ernst Bloch critica também as "frias e funcionais cidades modernas", de "arquitetura funcional", que não são mais espaços de moradia (Heimat) mas "máquinas de moradia" ${ }^{6}$, nivelando os sujeitos segundo o seu mecanismo de funcionamento. Isso faz desses sujeitos seres sem individualidade, cujas tensões são movidas por uma força externa.

Ao verem a sociedade cada vez mais fragmentada e seus indivíduos cada vez mais solitários, os românticos buscaram resistir à alienação das relações humanas e à destruição do ideal de comunidade que constituía a vida social moderna, movidos pelo desejo de reencontrar esse "lar", reestabelecer uma relação harmônica em comunidade, a antiga unidade que foi rompida:

4 LÖWY \& SAYRE, 2015, p. 66.

5 Ibidem, p. 43.

6 Ibidem, p. 246. 
E o desejo de recriar a comunidade humana - considerada de múltiplas formas: na comunicação autêntica com o outro, na participação no conjunto orgânico de um povo (Volk) e em seu imaginário coletivo expresso em mitologias e folclores, na harmonia social ou em uma sociedade sem classes - é a contrapartida do repúdio à fragmentação da coletividade da modernidade. (LÖWY \& SAYRE, 2015, p. 49)

Para recuperar a unidade perdida do povo, é preciso que se recupere a subjetividade e afetividade reprimidas dos indivíduos, que foram sacrificadas pela ordem. A reificação do homem compõe massas sem essência, sem história, são formas vazias de conteúdo. As multidões são compostas de anônimos fechados em si mesmos, "pobres almas que andam de um lado para o outro, mas não tem história” (BENJAMIN, 2017, p. 140). Os sujeitos desumanizados, desprovidos de memória, não conhecem mais a experiência autêntica (Erfahrung), histórica e cultural, mas somente a experiência imediata (Erlebinis) (LÖWY, 2005, p. 28).

A cidade faz o indivíduo confrontar uma grande quantidade de imagens e estímulos de forma rápida e incessante. No entanto, ele não tem capacidade de atribuir-lhes sentido tão rapidamente. Para se proteger da ameaça desse fluxo exterior, o habitante da cidade grande, segundo Simmel (1903), cria um “órgão protetor” que faz com que ele não reaja com o ânimo, mas com o entendimento lógico. No entanto, o homem movido pelo entendimento, tal como o princípio monetário, é indiferente pelo que é individual e subjetivo, pois este não é compreendido pela lógica racional. Dessa forma, a dissolução dos laços humanos qualitativos deriva dessa quantificação mercantil das relações.

Segundo Marshall Berman (2007), ainda no século XIX, Rousseau alerta seus contemporâneos das condições sociais que começavam a moldar a sociedade moderna, e define esta como um "redemoinho", "le tourbillon social". Esse vórtice da vida moderna, no qual ele tenta se locomover, impele o homem em direção à catástrofe, ao abismo, ao limite das contradições humanas. Em "A nova Heloísa”, o herói de Rousseau se sente solitário dentro da vida social moderna, incompreendido pelos seus semelhantes, perdido no "deserto da cidade" (LÖWY \& SAYRE, 2015, p. 66), e descreve a vida urbana como:

uma permanente colisão de grupos e conluios, um contínuo fluxo e refluxo de opiniões conflitivas. [...] Todos se colocam frequentemente em contradição consigo mesmos [...]. Com tal quantidade de objetos desfilando diante de meus olhos, eu vou ficando aturdido. De todas as coisas que me atraem, nenhuma toca o meu coração, embora todas juntas perturbem meus sentimentos, de modo a fazer que eu esqueça o que sou e qual meu lugar. (ROUSSEAU, 1761, p. 255-6 apud BERMAN, 2007, p. 27)

O excesso de informações que perpassam o sujeito faz ele se perder de si mesmo, "esquece o que é e qual o seu lugar" nesse meio. Na modernidade, como diria Marx, "tudo está impregnado de seu contrário". Ao mesmo tempo que a gama de possibilidades e a ruptura de fronteiras faz o homem ter uma liberdade nunca vista antes, esse turbilhão de coisas que o atraem, mas não o sensibilizam, carregam-o por um fluxo sob o qual ele perde o seu pró- 
prio controle. O sujeito, com sua subjetividade recalcada, é movido somente pelas tensões externas. Já no contexto da Guerra Fria, o american way of life representa essa influência do capital na vida do homem moderno. Com o final da Segunda Guerra Mundial, os Estados Unidos se consolidaram como grande potência econômica, e adotaram um plano de recuperação das economias capitalistas que foram assoladas pela guerra. Dessa forma, a promoção acerca dos privilégios norte-americanos fez com que o capitalismo se tornasse mais que um sistema econômico, mas uma visão de mundo, e o consumo de tornou um estilo de vida que representava a ideia de "liberdade", ideal que move os impulsos e o imaginário da sociedade moderna.

Diante do aniquilamento da subjetividade do indivíduo em nome da suposta liberdade da ordem capitalista, Allen Ginsberg traz em seus versos o lamento niilista de um sujeito americano que se vê perdido no centro do vórtice: “America I’ve given you all and now I'm nothing"7. O cultuado poema "Howl" é seu ganido de revolta contra a maquinaria capitalista e a lógica da civilização moderna, responsável pela destruição dos "expoentes da sua geração", invocando uma visão hedionda do Estado industrial moderno. Na segunda parte do poema, ele é representado a partir da imagem de "Moloch", deus cananeu-fenício adorado na colônia de Cartago, que tem como culto característico o sacrifício humano, principalmente de crianças, além da prostituição em nome do deus, fazendo do homem servo de seu templo:

What sphinx of cement and aluminum bashed open their skulls and ate up their brains and imagination?

Moloch! Solitude! Filth! Ugliness! Ashcans and unobtainable dollars! Children screaming under the stairways! Boys sobbing in armies! Old men weeping in the parks! $!^{8}$

(GINSBERG, 2014, p. 17)

Essa "esfinge", símbolo de poder e também de destruição, composta por "cimento e alumínio", base do cenário urbano, é a imagem da tirania moderna, que arruína "o cérebro e a imaginação" daqueles "expoentes", ameaçam sua liberdade de pensar e de ser. Nos extremos da sólida desigualdade que se institui no capitalismo, o sujeito se encontra solitário entre "latas de lixo e dólares inatingíveis". Em Moloch, todo homem é apenas mais um servo: o garoto continua sendo um objeto de sacrifício, seja nas escadarias do monumento de Moloch, seja servindo ao seu país na guerra.

A reação aos discursos da sociedade da literatura moderna de caráter romântico se traduz na permanente tensão entre a liberdade individual e os valores da ordem social. Em Moloch, a riqueza real do indivíduo é sacrificada em nome do desenvolvimento do capital. E as grandes cidades também podem serem vistas como um lugar de sacrifício humano, "um

7 "América eu te dei tudo e agora não sou nada" são os versos iniciais do poema "America”, presente na obra "Howl and other poems" (1956).

$8 \mathrm{Na}$ tradução de Claudio Willer: "Que esfinge de cimento e alumínio arrombou seus crânios e devorou seus cérebros e imaginação? Moloch! Solidão! Sujeira! Fealdade! Latas de lixo e dólares inatingíveis! Crianças berrando sob as escadarias! Garotos soluçando nos exércitos! Velhos chorando nos parques!” (GINSBERG, 2010, p. 34) 
santuário onde milhares passam anualmente pelo fogo como oferendas ao Moloch da avareza" . Em sua experiência na cidade de Londres, Engels relata que é possível notar "como esses londrinos tiveram de sacrificar a melhor parte de sua humanidade para levar a cabo todos os prodígios da civilização de que a cidade está cheia" (ENGELS, 1848, p. 36 apud BENJAMIN, 2017, p. 117).

A ideia de sacrifício humano relacionado aos valores quantitativos da sociedade e da metrópole moderno-capitalista é explorada por Ginsberg também em "Footnote to Howl" que, segundo o autor ${ }^{10}$, foi intitulado como "Nota de rodapé para Uivo" pois consistia numa variação extra da segunda parte do poema:

Holy the solitudes of skyscapes and pavements! Holy the cafeterias filled with the millions! Holy the mysterious rivers of tears under the streets!

Holy the lone juggernaut! Holy the vast lamb of the middle-class! Holy the crazy shepherds of rebellion! Who digs Los Angeles IS Los Angeles!

Holy New York Holy San Francisco Holy Peoria \& Seattle Holy Paris Holy Tangiers Holy Moscow Holy Istanbul! ${ }^{11}$

(GINSBERG, 2014, p. 21)

O poeta agora explora a imagem de Juggernaut, versão em inglês de Jagannath, uma das formas do deus hindu Vishnu, o "Senhor do Universo". Na Índia, essa divindade, feita em madeira, era levada em uma carruagem e exigia sacrifícios humanos, sendo novamente as crianças o objeto principal, que eram jogados sob as rodas da carruagem. Rev. Claudius Buchanan, um capelão anglicano defensor das missões cristãs na Índia, popularizou "the Juggernaut" entre os britânicos no século XIX, e utilizava a imagem de Moloch para explicar a imagem desse ídolo ao seu público ${ }^{12}$. O termo Juggernaut foi então incorporado à língua inglesa, com o sentido de uma força massiva inexorável, poderosa e destrutível, um movimento ou objeto que esmaga o que está em seu caminho.

A imagem púbere a ser sacrificada aparece no poema de Ginsberg logo em seguida, pelo "enorme cordeiro da classe média", animal que metaforicamente é sacrificado pelo bem comum. A ideia desenvolvida por Ginsberg em "Howl” e "Footnote to Howl” é de que os indivíduos se conduziram ao abate, são vítimas de si mesmos, de sua própria sociedade. A

9 "In no particular have the rights of persons been so avowedly and shamefully sacrificed to the rights of property, as in regard to the lodging of the labouring class. Every large town may be looked upon as a place of human sacrifice, a shrine where thousands pass yearly through the fire as offerings to the Moloch of avarice." (S. LAING, "National Distress; its causes and remedies", 1844, p. 150).

10 Cf. GINSBERG, A. Deliberate Prose: Selected Essays 1952-1995. New York: Harper Collins, 2000, p. 230.

11 Na tradução de Claudio Willer: "Santa a solidão dos arranha-céus e calçamentos! Santas as cafeterias cheias de milhões! Santo o misterioso rio de lágrimas sob as ruas! / Santo o solitário Jagarnata! Santo o enorme cordeiro da classe média! Santos os pastores loucos da rebelião! Quem saca que Los Angeles é Los Angeles! / Santo Nova York! Santo San Francisco Santo Peoria \& Seattle Santo Paris Santo Tânger Santo Moscou Santo Istambul!” (GINSBERG, 2010, p. 47)

12 Cf. ALTMAN, M. J. “The origins of the juggernaut”. In: <https://blog.oup.com/2017/08/origins-juggernaut-jagannath/>. Acesso em 06 de janeiro de 2019. 
sociedade era a culpada pela sua loucura, o homem foi prejudicado por um sistema impiedoso pelo qual ele, no entanto, é o responsável. Essa passagem da "inocência” à "experiência” é desenvolvida por William Blake em "Songs of Innocence and of Experience: Shewing the Two Contrary States of the Human Soul" (1789), obra de especial importância para Ginsberg, cujo mote será uma das bases do pensamento romântico: a infância é o estado de inocência do indivíduo, mas a experiência guia-o ao "mundo caído" e suas instituições.

No entanto, ainda persistem os embriões de resistência, elementos que ligam o presente ao passado, que guiam-nos por outros caminhos para além daquele ao qual somos arremessados. Podemos entender dessa forma as imagens apocalípticas do cordeiro e os "pastores loucos da rebelião", que evocam um mundo passado de inocência rural, como o Jardim do Éden antes da queda da humanidade, onde os indivíduos viviam em harmonia com a natureza. A imagem do pastor, além de representar a humanidade de uma vida próxima à natureza em contraste com a vida artificial da cidade, carrega também a influência da rebelião, representa o rebelde gênio marginal, a minoria que enfrenta as leis sociais, o "anjo caído" que se rebelou contra Deus.

Esse choque entre as imagens primitivas e as imagens urbanas que aparece nesses versos leva-nos a pensar no sofrimento do sujeito em sua relação desarmônica com o meio. San Francisco, Peoria, Seattle, Paris, Tangiers, Moscow, Istanbul: a cidade é o cenário principal da existência solitária que se origina da alienação das relações humanas. A solidão está "nos arranha-céus e calçamentos", e nas ruas há um "misterioso rio de lágrimas". O próprio Juggernaut é descrito como um ser "solitário". Ginsberg sente essa alienação de forma muito próxima aos românticos, que a viviam como um exílio, como se o homem fosse tirado de seu lar e vivesse em um estado de reclusão.

Segundo Löwy (2002), Max Weber representa a civilização capitalista através da alegoria da "gaiola de aço", na qual o homem é privado de sua liberdade própria. O capitalismo, para Weber, é como um "destino trágico" e "sem saída”, em que toda a humanidade encontra-se aprisionada. A "gaiola de aço" é, portanto, essa "estrutura reificada e alienada que encerra os indivíduos nas "leis do sistema" como em uma prisão" ${ }^{13}$. Voltando à parte II de "Howl", vemos que a imagem da prisão aparece entre as descrições de Moloch:

Moloch the incomprehensible prison! Moloch the crossbone soulless jailhouse and Congress of sorrows! Moloch whose buildings are judgment! Moloch the vast stone of war! Moloch the stunned governments! $!^{14}$ (GINSBERG, 2014, p. 17)

O indivíduo está, então, encarcerado nesta "prisão incompreensível” que é Moloch, nesse "presídio desalmado de ossos cruzados", comandado pelo "Congresso dos sofrimentos". Seus "edifícios são julgamento", e neles os homens são punidos, condenados ao cárcere por eles criado. Os confinados na suposta liberdade externa, proporcionada pelo sistema por eles edificado, têm sua liberdade interna encarcerada entre os muros da ordem. Como

13 LÖWY \& SAYRE, 2015, p. 9.

14 Na tradução de Claudio Willer: "Moloch a incomprensível prisão! Moloch o presídio desalmado de tíbias cruzadas e o Congresso dos sofrimentos! Moloch cujos prédios são julgamento! Moloch a vasta pedra da guerra! Moloch os governos atônitos!" (GINSBERG, 2010, p. 34) 
nas palavras de Berman (2007, p. 39): "não só a sociedade moderna é um cárcere, como as pessoas que aí vivem foram moldadas por suas barras; somos seres sem espírito, sem coração, sem identidade sexual ou pessoal - quase podíamos dizer: sem ser”. Movido pelas tensões externas e com suas tensões internas reprimidas, o homem moderno não existe como sujeito, mas como objeto.

Era preciso, então, resistir à torrente do "mundo da via expressa", e mostrar que este não constituía a única opção de existência. Allen Ginsberg, como vimos, desmistifica a imagem sublime acerca do ideal de vida moderno-burguês, mas seus versos não chegam a conceber um universo antagônico, em que o indivíduo possa recuperar a sua humanidade:

No final do último capítulo, invoquei "Uivo", o poema de Allen Ginsberg, para demonstrar como, no final dos anos 50, os modernistas começavam a enfrentar e combater o mundo da via expressa. [...] "Uivo" era brilhante ao desmascarar o niilismo demoníaco no âmago de nossa sociedade estabelecida e ao revelar o que Dostoievski um século antes definira como "a desordem, que é na realidade o grau mais elevado da ordem burguesa”. Todavia, tudo o que Ginsberg podia sugerir como alternativa à elevação de Moloch ao paraíso era o seu próprio niilismo. [...] Porém, se os incipientes modernistas dos anos 60 deviam virar o mundo ao contrário, eles precisavam oferecer alguma coisa a mais. (BERMAN, 2007, p. 368-9)

Tal como Berman, que aqui reconhece que Ginsberg oferece, como alternativa à condição humana que repudia, apenas “seu próprio niilismo", Umberto Eco (1991) também critica o protesto feito pelos beatniks em sua literatura. Eco afirma que se "reduz a salvação a uma espécie de contemplação do próprio vácuo"(ECO, 1991, p. 237), como se o ato de buscar uma solução constituisse "uma manifestação de cumplicidade com a situação". No entanto, a saída seria justamente "uma inserção prática e ativa na situação", já que, segundo Paz (2013), só a modernidade pode negar a si mesma. Dessa forma, ainda segundo Berman, os modernistas da década de 60 vão encontrar essa saída na vida cotidiana da rua. Energia moderna oposta à vida moderna, a desordem, que caracteriza a ordem burguesa, é também instrumento de resistência.

No Brasil, Roberto Piva vive essa experiência em seus versos, que percorrem as ruas da cidade de São Paulo anarquizando tudo aquilo que vêem pela frente para, então, compor o que Davi Arrigucci Jr. (2010) chama de "mundo delirante" de Piva. O poeta, que tinha Allen Ginsberg entre suas motivações literárias, continua a tradição de busca por reconstruir a unidade perdida, e utiliza da analogia para a construção de um outro universo com base na multiplicidade caótica constituinte desse universo ${ }^{15}$, e, assim, traz aquilo que os modernistas da década de 50, entre eles Ginsberg, não conseguiram alcançar.

Através da desordem, libertando os impulsos internos do sujeito que foram encarcerados pela des-ordem capitalista, Piva se coloca em oposição às "construções do industrialismo e da modernização conservadora, cuja face predatória vê encarnada na Babilônia

15 ARRIGUCCI JR., 2010, p. 43. 
capitalista que é São Paulo" (ARRIGUCCI JR., 2010, p. 43). A cidade de São Paulo não é somente um espaço, mas também uma ideia, uma alegoria que representa a decadência da modernidade pela avidez do progresso. Em sua obra de estreia, "Paranoia" (1963), seu modo de olhar o espaço urbano permite que as barreiras entre o derrotismo e o otimismo sejam transcendidas, uma vez que o poeta-personagem exalta os traços de humanidade que permanecem vivos nos pequenos detalhes do ambiente que parece devastado, reunindo esses fragmentos de forma a criar um outro ambiente.

O poema "Paranoia em Astrakan", cujos versos são inspirados no anteriormente analisado "Howl" de Ginsberg, apresenta um ângulo diferente daquele descrito por Ginsberg, que expressa o lamento sobre "quem" ${ }^{16}$ foi afligido pelo ambiente demoníaco moderno-capitalista. Neste poema, Piva descreve a visão de um ambiente antagônico, “onde” os fragmentos desse real compõem as imagens do sonho:

Eu vi uma linda cidade cujo nome esqueci

onde anjos surdos percorrem as madrugadas tingindo seus olhos com lágrimas invulneráveis

onde crianças católicas oferecem limões para pequenos paquidermes que saem escondidos de suas tocas

onde adolescentes maravilhosos fecham seus cérebros para os telhados estéreis e incendeiam internatos

onde manifestos niilistas distribuindo pensamentos furiosos puxam a descarga sobre o mundo

onde um anjo de fogo ilumina os cemitérios em festa e a noite caminha no seu hálito

[...]

onde o nosso desprezo fez nascer uma lua inesperada no horizonte branco onde os mortos se fixam na noite e uivam por um punhado de fracas penas onde a cabeça é uma bola digerindo os aquários desordenados da imaginação (PIVA, 2000, p. 27-30)

A "linda cidade" que vê Piva não possui nome, o que permite que qualquer cidade possa sê-la. Essa cidade é composta por figuras de diferentes esferas, oscilando entre o baixo e o elevado, fazendo-as se confundirem entre si. Da figura sagrada dos anjos, passa pela genuinidade das "crianças católicas" e adolescentes no alvor da vida, até a figura rebaixada dos mortos. Os sórdidos "cemitérios em festa" podem ser os próprio espaços urbanos da metrópole-necrópole, morada dos que foram aniquilados pelo mundo burguês moderno. Seus mortos "se fixam na noite e uivam por um punhado de fracas penas", e podem corresponder às "best minds" representadas por Ginsberg, "que uivaram ajoelhados no metrô e foram arrastados do telhado agitando genitais e manuscritos".

16 Os versos de "Howl" são iniciados por "who": "I saw the best minds of my generation destroyed by madness, starving hysterical naked / [...] who poverty and tatters and hollow-eyed $[\ldots] /$ who bared their brains $[\ldots]$ ”. 
Ao circular entre diferentes esferas em um mesmo espaço, o poeta subverte a lógica e explora o desconhecido, que pode ser representado também pela imagem da "noite" e da "madrugada" - sendo essa última equivalente também à ideia de alvorada, de princípio -, elemento por excelência romântico que, segundo Candido (2006), é um momento favorável ao sobrenatural e ligado ao inconsciente. O ambiente noturno remete ao "fascínio romântico pela noite, como lugar de sortilégio, mistério e magia, que os escritores e poetas contrapõem à luz, emblema clássico do racionalismo" (LÖWY \& SAYRE, 2015, p. 54).

Em oposição ao que é colocado à luz, pois, que Piva vai explorar as sombras, aquilo que foi obscurecido pela racionalidade burguesa. Na sua "linda cidade", "manifestos niilistas" que distribuem "pensamentos furiosos" - que podem ser relacionados, por exemplo, à própria literatura beat, como a poesia de Ginsberg - "puxam a descarga sobre o mundo", lançando sobre nós os dejetos, trazendo à luz tudo o que é evacuado pelo ralo do capitalismo. A visão de Piva sobre a cidade nos mostra a beleza que existe em sua sujeira, e aproxima a pureza à impureza, como as "crianças católicas" com os "pequenos paquidermes", indivíduos calejados cuja desumanização aproxima-os do animalesco, "que saem escondidos de suas tocas".

Nos poemas de "Paranoia", a justaposição de realidades opostas cria um tom de alucinação em suas imagens, que correspondem à uma aderência ao mundo vital à partir de um retorno às primeiras operações sensíveis, à harmoniosa unidade dos contrários, que resulta numa consubstanciação epifânica:

O sonho, o delírio, a hipnose e outros estados de relaxamento da consciência favorecem o fluir das frases. A corrente parece não ter fim: uma frase nos leva a outra. Arrastados pelo rio de imagens, chegamos às margens do puro existir e adivinhamos um estado de unidade, de união final com nosso ser e o ser do mundo. (PAZ, 2012, p. 59)

Através de suas imagens, o poeta manifesta o desejo de saltar para um outro lado, de existir de outra forma. O poeta sonha acordado, e pela conjunção de sonho e realidade ele pretende transformar a vida. O poema "Praça da República dos meus Sonhos" é um dos que Piva explora declaradamente a esfera do sonho, manifestação que, segundo Candido (2006), era de grande importância para os românticos "como fonte eventual de uma existência diferente", como "uma segunda via":

A estátua de Álvares de Azevedo é devorada com paciência pela paisagem de morfina

a praça leva pontes aplicadas no centro de seu corpo e crianças brincando na tarde de esterco

Praça da República dos meus sonhos

onde tudo se fez febre e pombas crucificadas

onde beatificados vêm agitar as massas

onde Garcia Lorca espera seu dentista

onde conquistamos a imensa desolação dos dias mais doces 
os meninos tiveram seus testículos espetados pela multidão

lábios coagulam sem estardalhaço

os mictórios tomam um lugar na luz

e os coqueiros se fixam onde o vento desarruma os cabelos

Delirium Tremens diante do Paraíso bundas glabras sexos de papel

anjos deitados nos canteiros cobertos de cal água fumegante nas

privadas cérebros sulcados de acenos

os veterinários passam lentos lendo Dom Casmurro

há jovens pederastas embebidos em lilás

e putas com a noite passeando em torno de suas unhas

há uma gota de chuva na cabeleira abandonada

enquanto o sangue faz naufragar as corolas

Oh minhas visões lembranças de Rimbaud praça da República dos meus

Sonhos última sabedoria debruçada numa porta santa

(PIVA, 2000, p. 57-8)

Segundo Peixoto (1996), a praça, para o passante solitário, não é um lugar, mas uma paisagem, o lugar dos que não tem lugar. Para Kant, a paisagem ocore "toda vez que o espírito se desprende de uma matéria sensível para outra" (PEIXOTO, 1996, p. 521), é uma imagem desenraizada que é sobreposta a todo momento. Dessa forma, a metrópole, com sua grande quantidade de imagens e estímulos contínuos, faz todos os espaços serem somentes paisagens. Em seus versos, Piva faz com que a paisagem da praça se transfigure em espaço, e realiza uma suspensão do fluxo contínuo e uniforme da sociedade. Espaço aberto ao redor do qual a vida urbana se desenvolve, a praça não é um espaço somente de trânsito ou de consumo, mas de vivências, um centro de convívio social integrado ao claustrofóbico ambiente urbano, que permite que os transeuntes se acomodem e interajam entre si. A sua liberdade permite que os mais variados tipos de pessoas estejam em comunhão, de crianças à putas e "jovens pederastas", e que a sujeira seja tirada de debaixo do tapete higienista do progresso, e, assim, "os mictórios tomam um lugar na luz".

A construção fragmentária do poema, onde se intercalam memórias do passado e imagens do presente, cria um efeito de ruínas de uma totalidade perdida. Ele se inicia com a energia apática da estátua do romântico Álvares de Azevedo sendo "devorada com paciência pela paisagem de morfina", sendo ao poucos suprimida pela indiferença da paisagem anestesiada. Situações cotidianas se misturam com rememorações literárias, como García Lorca esperando seu dentista, ou os veterinários que "passam lentos lendo Dom Casmurro" - estando o ritmo deste último verso em consonância com o ritmo da ação nele descrita. Tanto a poesia de García Lorca, quanto "Dom Casmurro" de Machado de Assis, são obras que recorrem ao sentimento de nostalgia, ao impulso do desejo causado pela falta da unidade perdida, a fim de, através da memória, retornar à esse ambiente do qual foi expulso. A Praça da República, por despertar essa dor nostálgica, é um espaço “onde conquistamos a imensa desolação dos dias mais doces".

A memória é sensorial e está cravada na matéria. Existe como estilhaços, não como totalidade. A repetição paralelística, recurso conhecido pelo seu uso nos versos livres de Walt 
Whitman, é explorada por Piva em "Praça da República dos meus Sonhos”, tal como no poema "Paranoia em Astrakan", pela repetição de versos principiados pelo pronome relativo "onde", e cria um efeito de unidade entre os elementos por ela reunidos. Já o verso "Delirium Tremens diante do Paraíso bundas glabras sexos de papel anjos deitados nos canteiros cobertos de cal água fumegante nas privadas cérebros sulcados de acenos" é envolvido por um ritmo vertiginoso, e numa torrente de imagens desconexas o poeta se aproxima do estado alucinatório de "Delirium Tremens". Para atingir esse efeito, Piva utiliza de enumerações, recurso também conhecido pela poesia de Whitman, que, segundo Leo Spitzer (1989), tem como princípio a integração de elementos heterogêneos e desconexos para a reconstrução do todo-uno da natureza.

Esses recursos formais são, portanto, um meio de negação à desordem do mundo criado pela civilização moderna. Busca-se romper com o sentimento de isolamento e exílio em que se encontra o indivíduo autômato, que teve aniquilada a sua memória, perdido no meio do vórtice da vida moderna. Para isso, o poeta representa como tudo coexiste dentro do caos original, como as relações sensíveis não conseguem ser reduzidas às fronteiras do presente, ao olhar exíguo do progresso. Para ter acesso ao conhecimento da infinitude do homem, é necessário que "as portas da percepção fossem limpas", pois os limites estabelecidos pela consciência humana fazem com que se vejam "todas as coisas através de frestas estritas de sua caverna" ${ }^{17}$. E isso se faz materializado na praça da República dos sonhos de Piva, a "última sabedoria debruçada numa porta santa", porta que limita e permite o acesso do mundo profano ao mundo sagrado, onde os dois mundos se comunicam.

$\mathrm{Na}$ busca de romper esse isolamento entre diferentes tempos e espaços, a fragmentação da linguagem poética simboliza, ao mesmo tempo, a incompletude do indivíduo que foi separado de sua natureza e a pluralidade que compõe esse espaço, quando concebido em sua totalidade. Composta de acúmulo e vazio, construção e ruína, desejo e impossibilidade, a poesia é a tentativa de comunicar o incomunicável. E uma forma de expressar o indizível é através do olhar visionário, experiência que, segundo Wisnik (1988), resulta do apagamento da visão habitual, e excede o foco e os limites do ego. Através do olhar visionário, Piva faz do poema "Visão de São Paulo à noite - Poema Antropófago sob Narcótico" um retrato oracular do turbilhão de sensações que a cidade de São Paulo lhe desperta.

Partindo, a princípio, do próprio título do poema, vemos que certas ideias já mencionadas tornam a aparecer, como a imagem da noite, ambiente de mistério, um abismo de imagens em que nos lançamos à deriva. A noite revela tudo aquilo que é ocultado pela luz da razão, e desaparecem os limites da norma. Em uma de suas narrativas de experiências com narcóticos reunidas na obra "On Hashish", Benjamin relata que, à noite, as visões se distanciam da vivência (Erlebinis), experiência momentânea e alienada, se aproximando então da experiência autêntica (Erfahrung) ${ }^{18}$. Todos os indivíduos estão ligados pela unidade da

17 A citação se refere à um trecho de "O matrimônio do Céu e do Inferno" (Iluminuras, 1987) de William Blake: "If the doors of perception were cleansed everything would appear to man as it is, Infinite. For man has closed himself up, till he sees all things through narrow chinks of his cavern."

18 "What one writes down the following day is more than an enumeration of momentary experiences [Erlebnis]. In the night, the trance sets itself off from everyday experience [Erfahrung] with fine, prismatic edges." (BENJAMIN, 2006, p. 53) 
história coletiva, e o resgate de nossa essência perdida pode reunir o que foi separado. Dessa forma, neste poema antropófago, Piva revela o estado primitivo de selvageria que ainda corre nas artérias da metrópole paulistana, prega a libertação dos instintos, seguindo a pura antropofagia do ato de devorar o outro, e transforma sua visão num ritual.

Logo no primeiro verso se fazem presentes os elementos ritualísticos: "Na esquina da rua São Luís uma procissão de mil pessoas acende velas no meu crânio". O cenário principal do poema é a rua São Luís, região que, segundo Claudio Willer, era "um febril cruzamento de vida cultural, boemia e desfile de toda sorte de tipos”, e que abrigava a Galeria Metrópole, ponto em que se localizava a vida noturna underground e intelectual da década de 1960, e onde costumavam se encontrar Piva, Willer, entre outros. A rua São Luís, pequena via no centro da metrópole, que por muito tempo manteve sua tradição, mas que na metade do século XX entrou em processo de verticalização, respirava ainda uma vida social autêntica.

$\mathrm{Na}$ rua São Luís há a voz e o silêncio, a presença e o abandono. Tudo coexiste nesse ambiente. A organicidade das relações é representada em imagens como dos "amantes chupando-se como raízes", que se devoram numa relação de interdependência substancial, assimilando a noção de gênese através de uma perspectiva erótica. O indivíduo não se limita ao seu eu egoísta, mas existe de forma consubstancial com o outro, e também com o próprio espaço. O eu compõe o próprio cenário, ao ponto de sujeito e objeto serem representados ao revés: "sou ponte de granito sobre rodas de garagens subalternas", "torneiras tossindo, locomotivas uivando, adolescentes roucos / enlouquecidos na primeira infância", "eu sinto o choque de todos os fios saindo pelas portas / partidas do meu cérebro".

São Paulo é o que Piva resume no poema como "reino-vertigem glorificado", já que a "vertigem" combina por si só a noção de delírio, de movimento acelerado, e também de violência, de ferocidade. Enquanto a "cidade com chaminés" cresce, nenhuma sensação passa despercebida pelo poeta, que sente "o choque de todos os fios saindo pelas portas partidas" do seu cérebro, absorve e digere tudo o que atravessa o seu olhar: "eu vejo putos putas patacos torres chumbo chapas chopes / vitrinas homens mulheres pederastas e crianças cruzam-se e / abrem-se em mim como lua gás rua árvores lua medrosos repuxo”. As enumerações são novamente utilizadas por Piva para compor uma visão surreal do todo unificado a partir da miríade de fragmentos que se cruzam. A aliteração dos sons de "p", "b", "t" e "ch" e a ausência de pontuação produz um ritmo ágil que encarna o ritmo da cidade. Logo, a partir do momento em que o poeta exclama "eu vejo...", o poema ganha um tom violento:

colisão na ponte cego dormindo na vitrina do horror disparo-me como uma tômbola a cabeça afundando-me na garganta chove sobre mim a minha vida inteira, sufoco ardo flutuo-me nas tripas, meu amor, eu carrego teu grito como um tesouro afundado quisera derramar sobre ti todo meu epiciclo de centopeias libertas ânsia fúria de janelas olhos bocas abertas, torvelins de vergonha, correrias de maconha em piqueniques flutuantes vespas passeando em voltas das minhas ânsias meninos abandonados nus nas esquinas 
angélicos vagabundos gritando entre as lojas e os templos

entre a solidão e o sangue, entre as colisões, o parto

e o Estrondo

(PIVA, 2000, p. 42-45)

O poeta é tomado pelo fôlego dionisíaco, que aniquila impiedosamente os limites da existência impostos pela ordem social. Tudo parece colidir, e entra em estado de colapso. O tempo perde sua linearidade progressiva, imerge no passado da experiência pessoal, e o poeta é banhado pela sua memória: "chove sobre mim a minha vida inteira, sufoco ardo flutuo-me". A memória do Outro, num ato antropofágico, se mantém viva no interior do Eu: "nas tripas, meu amor, eu carrego teu grito como um tesouro afundado". E, por fim, soa o grito dos "angélicos vagabundos" no centro do vórtice de contrários, que do "parto" culmina num "Estrondo". Ao contrário de T.S. Eliot, que, ao fim de "The Hollow Men", decreta a falência da humanidade ao revelar que o mundo acaba "não com uma explosão, mas com um suspiro"19, Piva revela que ainda existe paixão numa sociedade que teve sua humanidade arruinada.

Pode-se concluir, portanto, que Roberto Piva tenta conceber um novo ambiente, humanizado, a partir dos farrapos da estrutura em decomposição dessa "Atlântida perdida" que um dia foi a cidade de São Paulo, hoje "periférica, suja, feia, degradada a cada enchente repetida", mas que "dos seus detritos desconjuntados, dos dejetos cumulativos do desenvolvimento desigual e da luta feroz pela riqueza, que ele consegue extrair, a duras custas, a magia de um ouro mais raro, o que a poesia consegue cunhar com as palavras" (ARRIGUCCI JR., 2010, p. 5). Aos olhos de Piva, são nas suas características subdesenvolvidas, que fazem-a parecer arruinada, envelhecida, que irradia uma delicadeza singular. E nos traços de humanidade que ainda sobrevivem nestes escombros nasce uma outra esperança de preencher o vazio existencial que perturba nossa humanidade.

\section{REFERÊNCIAS}

ANDRADE, Oswald de. Obras Completas VI: Do Pau-Brasil à Antropofagia e às Utopias. 2 ed. Rio de Janeiro: Civilização Brasileira, 1978.

ARRIGUCCI JR., Davi. O guardador de segredos. São Paulo: Companhia das Letras, 2010.

BENJAMIN, Walter. Baudelaire e a modernidade. Ed. e trad. João Barrento. Belo Horizonte: Autêntica, 2017.

On Hashish. Trad. Howard Eiland. Cambridge: Harvard University Press, 2006.

BERMAN, Marshall. Tudo o que é sólido desmancha no ar: A aventura da modernidade. Trad. Carlos Felipe Moisés e Ana Maria L. Ioriatti. São Paulo: Companhia das Letras, 2007.

19 This is the way the world ends / Not with a bang but a whimper" 
BLAKE, William. O matrimônio do Céu e do Inferno; O livro de Thel. Trad. José Antônio Arantes. São Paulo: Iluminuras, 1987.

CANDIDO, Antonio. Romantismo, negatividade, modernidade. Anuario del Colegio de Estudios Latinoamericanos. Universidad Nacional Autónoma de México. Vol. 01, 2006, p. 137-141.

COHN, Sergio. (Org.). Encontros: Roberto Piva (Entrevistas). Rio de Janeiro: Azougue, 2009.

ECO, Umberto. Obra aberta: forma e indeterminação nas poéticas. Trad. Giovanni Cutolo. São Paulo : Perspectiva, 1991.

FRYE, Northrop. Anatomia da Crítica. Trad. Péricles Eugênio da Silva Ramos. São Paulo: Cultrix, 1973.

GINSBERG, Allen. Deliberate Prose: Selected Essays 1952-1995. New York: Harper Collins, 2000 . Howl and other poems. Mansfield Centre: Martino Publishing, 2014.

. Uivo, Kadissh e outros poemas. Trad. Claudio Willer. Porto Alegre: L\&PM, 2010.

HUNGRIA, C; D'ELIA, R. Os dentes da memória - Piva, Willer, Franceschi, Bicelli e uma trajetória paulista de poesia. Rio de Janeiro: Azougue, 2011.

LÖWY, Michael. A estrela da manhã: surrealismo e marxismo. Trad. Eliana Aguiar. Rio de Janeiro: Civilização Brasileira, 2002.

Walter Benjamin - Aviso de incêndio: uma leitura das teses "Sobre o conceito de história". São Paulo: Boitempo, 2005.

LÖWY, M; SAYRE, R. Revolta e melancolia: o romantismo na contracorrente da modernidade. Trad. Nair Fonseca. 1 ed. São Paulo: Boitempo, 2015.

PAZ, Octavio. O arco e a lira. Trad. Ari Roitman e Paulina Wacht. São Paulo: Cosac Naify, 2012.

. Os filhos do barro: do romantismo à vanguarda. Trad. Ari Roitman e Paulina Wacht. São Paulo: Cosac Naify, 2013.

PEIXOTO, Nelson Brissac. "Cidades desmedidas". In: NOVAES, Adauto (Org.). A crise da razão. São Paulo: Companhia das Letras, 1996, pp. 519-534.

PIVA, Roberto. Paranoia. São Paulo: Instituto Moreira Salles, 2000. 
SIMMEL, Georg. As grandes cidades e a vida do espírito (1903). Mana. Rio de Janeiro. Vol.11, n.2, oct. 2005.

SPITZER, Leo. "La enumeración caótica en la poesía moderna". In : . Linguística e historia literaria. 2 ed. Madrid: Editorial Gredos, 1989, pp. 247-291.

WISNIK, José Miguel. "Iluminações profanas (poetas, profetas, drogados)”. In: NOVAES, Adauto (Org.). O olhar. São Paulo: Companhia das Letras, 1988, pp. 283-299. 
